\title{
Induction and Recovery of the Viable but Nonculturable State of Hop-Resistance Lactobacillus brevis
}

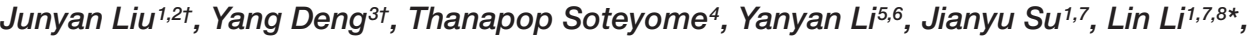

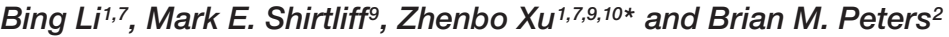

${ }^{1}$ School of Food Science and Engineering, South China University of Technology, Guangzhou, China, ${ }^{2}$ Department of Clinical Pharmacy, College of Pharmacy, University of Tennessee Health Science Center, Memphis, TN, United States, ${ }^{3}$ College of Food Science and Engineering, Qingdao Agricultural University, Qingdao, China, ${ }^{4}$ Home Economics Technology, Rajamangala University of Technology Phra Nakhon, Bangkok, Thailand, ${ }^{5}$ Department of Cell Biology, Harvard Medical School, Boston, MA, United States, ${ }^{6}$ State Key Laboratory of Food Science and Technology, Jiangnan University, Wuxi, China, ${ }^{7}$ Guangdong Province Key Laboratory for Green Processing of Natural Products and Product Safety, Guangzhou, China, ${ }^{8}$ School of Chemical Engineering and Energy Technology, Dongguan University of Technology, Dongguan, China, ${ }^{9}$ Department of Microbial Pathogenesis, School of Dentistry, University of Maryland, Baltimore, MD, United States, ${ }^{10}$ Overseas Expertise Introduction Center for Discipline Innovation of Food Nutrition and Human Health (111 Center), Guangzhou, China
\end{abstract}

OPEN ACCESS

Edited by:

Liang Xue,

Guangdong Institute of Microbiology (CAS), China

Reviewed by: Cristiana Garofalo, Università Politecnica delle Marche,

Italy

Moutong Chen, Guangdong Institute of Microbiology

(CAS), China

*Correspondence:

Lin L

felinli@scut.edu.cn

Zhenbo Xu

zhenbo.xu@hotmail.com

tThese authors have contributed equally to this work

Specialty section: This article was submitted to

Food Microbiology a section of the journal

Frontiers in Microbiology

Received: 09 February 2018 Accepted: 14 August 2018 Published: 15 October 2018

Citation:

Liu J, Deng Y, Soteyome T, Li Y, SU J, Li L, Li B, Shirtliff ME, XU Z and

Peters BM (2018) Induction and Recovery of the Viable but Nonculturable State of Hop-Resistance Lactobacillus brevis. Front. Microbiol. 9:2076. doi: 10.3389/fmicb.2018.02076
Lactobacillus brevis is a major hop-resistance bacterium which poses significant challenge for the brewing industry, mainly due to the difficulty or incapability in detection by routine culturing methodology and its beer spoilage ability. This study aimed at investigating the VBNC state of a hop-resistance strain, L. brevis BM-LB13908. The culturable, total and viable numbers of $L$. brevis cells were calculated by MRS agar plate counting, acridine orange direct count (AODC) method and Live/Dead BacLight bacterial viability kit with fluorescence microscope. VBNC formation was induced by $189 \pm 5.7$ days under low-temperature storage or $27 \pm 1.2$ subcultures by continuous passage in beer, and VBNC cells induced by both strategies were recovered by adding catalase. In addition, insignificant difference in beer-spoilage ability was found in 3 states of $L$. brevis, including logarithmic growing, VBNC and recovered cells. This is the first study on the formation of VBNC state for $L$. brevis and beer-spoilage ability of both VBNC and recovered cells, which indicate $L$. brevis strain could cause beer spoilage without being detected by routine methodologies. The results derived from this study may support further study on L. brevis and other hop-resistance bacteria, and guidance on beer spoilage prevention and control, such as improvement for brewers on the microbiological quality control by using the improved culture method with catalase supplementation.

Keywords: Lactobacillus brevis, VBNC state, hop-resistance, beer spoilage, VBNC cells recovery

\section{INTRODUCTION}

As one of the most common beverage, beer has high microbiological stability and is considered to be safe, as it contains various microorganisms unable to survive in beer. Beer contains high ethanol $(0.5$ to $10 \% \mathrm{w} / \mathrm{w})$ and carbon dioxide concentration (approximately $0.5 \% \mathrm{w} / \mathrm{w})$, low $\mathrm{pH}(3.8-4.7)$, low concentrations of nutritive substances and extremely low oxygen content $(<0.1 \mathrm{ppm})$, as well as hop bitter compounds (approximately 17-55 ppm of iso- $\alpha$-acids) (Sakamoto and Konings, 2003; Suzuki et al., 2006). Hop components serve the desirable bitter flavor, characteristic aroma, and apply bacteriostatic effects on most Gram-positive bacteria (Simpson and Fernandez, 1992, 1994; 
Simpson, 1993). However, in spite of such unfavorable conditions for growth of microorganisms, a number of bacterial species (primarily Lactobacilli) are tolerant to hop compounds and capable of growing in hopped beer, thus designated as hopresistance bacteria. Some Lactobacilli have been well studied and established to be one of the leading causes of turbidity and acidity in beer. In addition, formation of the viable but nonculturable (VBNC) state under extreme environments enables Lactobacilli strains to cause false-negative detection (Suzuki et al., 2006; Deng et al., 2015). VBNC cells are incapable of either growth on routine bacteriological culturing media or formation of normal colonies, but remain viable and retain metabolic activity (Oliver, 2005). If beer contaminated by VBNC strains has been delivered to commercial markets, even small numbers of hopresistance bacteria will recover and eventually impart off-flavor and turbidity to beer. Up to date, five species of Lactobacillus strains have been verified for formation of VBNC state, including L. lindneri (Suzuki et al., 2006; Liu et al., 2017a), L. casei (Liu et al., 2017c), L. plantarum (Liu et al., 2017b), L. paracollinocides (Suzuki et al., 2006) and L. acetotolerans (Deng et al., 2015), which had been induced to enter into the VBNC state by beer subculture treatment or low-temperature storage.

As an important and most frequently discovered beer spoilage bacterium, Lactobacillus brevis is capable of producing end or by products of carbohydrate fermentation including lactic acid and acetic acid as significant influential factors on the flavors of beer, as well as biogenic amines which are associated with food intoxication, blood pressure increasing, migraines, dystonias, Parkinson's disease, schizophrenia, drug addiction, mental disorders and neurodegenerative disease (Premont et al., 2001; Marcobal et al., 2006; Miao et al., 2017; Xu et al., 2017; Lin et al., 2018). L. brevis has been frequently identified within the beer sector as a spoilage bacterium (Garofalo et al., 2015), which is also physiologically versatile and responsible for various concerns in beer such as super-attenuation due to its fermentation of dextrins and starch (Lawrence, 1988). Importantly, L. brevis is commonly resistant to hop compounds, and the antibacterial effects of hop compounds and the mechanism(s) responsible for hop resistance have been previously studied in L. brevis strains (Suzuki et al., 2002).

This study aimed to investigate the induction, recovery and beer-spoilage capacity of VBNC state L. brevis strain BMLB13908 which shows strong resistance to hop compounds.

\section{MATERIALS AND METHODS}

\section{Bacterial Strains and Growth Conditions}

The present L. brevis strain (designated BM-LB13908) had been isolated from finished beer sample $(\mathrm{pH} 4.5$, ethanol $\geq 3.6 \% \mathrm{v} / \mathrm{v}$, bitterness units seven) and maintained as a glycerol stock stored at $-80^{\circ} \mathrm{C}$. Whole genome sequencing was performed for this strain and the draft genomic sequence was deposited in GenBank under accession number LTDY00000000. L. brevis BM-LB13908 shows strong hop resistance and contains the hop resistant gene horA in its genome. A small amount of stock was spread onto MRS agar (Oxoid, United Kingdom) and incubated at $26^{\circ} \mathrm{C}$ for
3 days to obtain isolated colonies. A single colony was transferred to $1 \mathrm{~mL}$ of MRS broth and incubated anaerobically at $26^{\circ} \mathrm{C}$ for $24 \mathrm{~h}$ prior to further experiments.

\section{Formation of VBNC State}

Based on the environment beer-spoilage bacteria encountered during beer brewing (continuous passage) and storage (lowtemperature), two strategies, including low-temperature storage and continuous passage in beers were selected to conduct the formation of VBNC state of strain L. brevis BM-LB13908. Low temperature or cold treatment have also been frequently reported to induce the VBNC formation of various bacteria in previous studies (Mary et al., 2002; Gupte et al., 2003; Kong et al., 2004, 2014; Sun et al., 2008; Dinu and Bach, 2011; Griffitt et al., 2011; Patrone et al., 2013; Zeng et al., 2013; Magajna and Schraft, 2015; Liu et al., 2017d). For the former, cells of L. brevis BM-LB13908 in logarithmic growth phase were harvested at $4^{\circ} \mathrm{C}$ (centrifugation at $5000 \mathrm{rpm}$ for $15 \mathrm{~min}$ ) and washed twice with phosphate buffer (PBS). Then the washed cells were filtered through a $0.22 \mu \mathrm{m}$ Millipore membrane filter and resuspended in $10 \mathrm{~mL}$ of degassed beer at a final density of $10^{7}$ cells $/ \mathrm{mL}$. The bacterial cells were further maintained at $0^{\circ} \mathrm{C}$ for the formation of VBNC state.

Continuous passage in beer was performed as described previously (Deng et al., 2015), with slight modification. In brief, approximately $10^{7}$ cells of L. brevis BM-LB13908 in logarithmic growth phase were harvested at $4^{\circ} \mathrm{C}$ (centrifugation at $5000 \mathrm{rpm}$ for $15 \mathrm{~min}$ ) and washed twice with PBS. Then the washed cells which marked as $0^{\#}$ subculture were resuspended by $10 \mathrm{~mL}$ of degassed beer at a final density of $10^{7}$ cells $/ \mathrm{mL}$ and anaerobically cultured at $26^{\circ} \mathrm{C}$. After 7 days incubation, the cells were marked as $1^{\#}$ subculture and harvested, washed, and resuspended in $10 \mathrm{~mL}$ of fresh degassed beer. The process was repeated every 7 days.

\section{Cell Populations Quantification}

In the current study, the definition of "VBNC state" is the incapability of microbial growth on MRS agar until 3 days of incubation at $26^{\circ} \mathrm{C}$. For both induction processes, the culturable cell number was accessed by inoculating $100 \mu \mathrm{L}$ of bacterial culture on MRS agar according to a conventional plate culture procedure (Suzuki et al., 2008). After 3 days of incubation at $26^{\circ} \mathrm{C}$, cell culturability was determined by CFU counting.

Number of total cells was determined every 7 days by AODC method (Hobbie et al., 1977). In brief, bacterial cultures were centrifuged and washed twice with PBS. Then the washed cell samples were serially diluted in $0.5 \mathrm{M}$ sodium $\mathrm{PBS}$ at $\mathrm{pH} 7.0$, fixed with formalin (final concentration, $2 \% \mathrm{v} / \mathrm{v}$ ), and stained with $0.01 \% \mathrm{w} / \mathrm{v}$ acridine orange. After $2 \mathrm{~min}$ incubation, the suspension was filtered onto a $0.22 \mu \mathrm{m}$ Millipore membrane filter. The filter was then examined under an Olympus BH-2 fluorescence microscope (Olympus, Japan).

Cellular viability determination was further conducted by the Live/Dead BacLight bacterial viability kit (Molecular Probes, United States), followed by observation under fluorescent microscope (Berney et al., 2007). In brief, the fluorescent dyes propidium iodide (20 mM in DMSO) and SYTO 9 (3.34 mM in DMSO) were mixed in a 2:1 ratio. Washed cell samples 

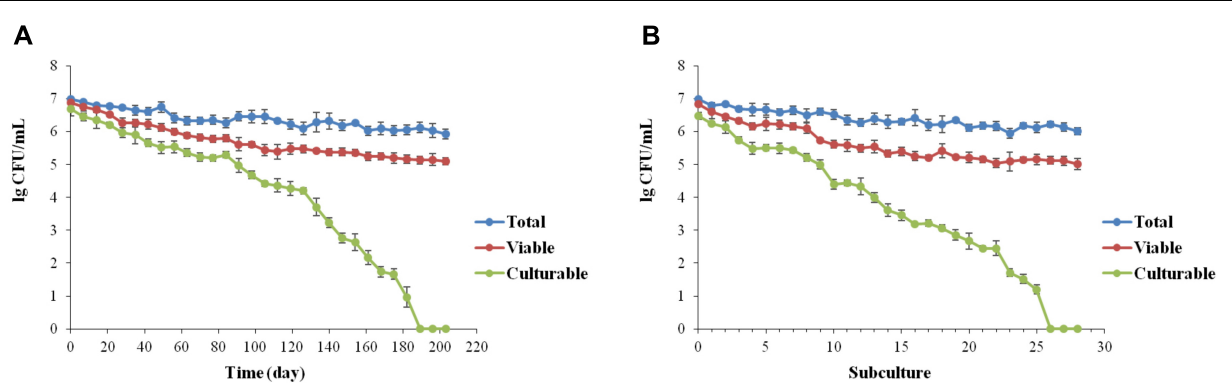

FIGURE 1 | Induction of the VBNC state of Lactobacillus brevis BM-LB13908 by low-temperature storage $\left(0^{\circ} \mathrm{C}\right)(\mathbf{A})$ or continuous passage in beer (B), respectively.

$(500 \mu \mathrm{L})$ were stained with $1.5 \mu \mathrm{L}$ of dye mixture at room temperature in the dark for $20 \mathrm{~min}$. Stained cell samples were then immediately filtered onto a $0.22 \mu \mathrm{m}$ Millipore membrane filter. The filters were placed on glass slides with $10 \mu \mathrm{L}$ mounting oil (Millipore) followed by sealing of the coverslips. Slides were immediately taken for viewing under an Olympus BH-2 fluorescence microscope (Olympus, Japan). Cellular culturability and viability measurement were performed once a week.

\section{Recovery of the VBNC Cells}

After the VBNC state induction process, chemicals addition was performed for recovery of VBNC L. brevis cells. Oxidative stress was encountered by the VBNC L. brevis cells under low temperature and harsh beer condition (Chattopadhyay et al., 2011), adding catalase was applied to relief the oxidative stress and promote the recovery of VBNC cells (Jallouli et al., 2010; Kong et al., 2014). Tween and vitamins, which have been reported to successfully recover VBNC bacteria, especially beer spoilage bacteria (Ramaiah et al., 2002; Sakamoto and Konings, 2003), were also used. One hundred microliters of L. brevis VBNC cells induced by either strategies were plated onto MRS agar supplemented with Tween-20, Tween-80, vitamin C, vitamin B2, and catalase (Sigma-Aldrich, United States) at final concentrations of $0.1 \%, 0.1 \%, 5 \mathrm{~g} / \mathrm{L}, 5 \mathrm{~g} / \mathrm{L}$, and $800 \mathrm{U} /$ plate. Simultaneously, MRS agar with no supplements and addition of heat $\left(60^{\circ} \mathrm{C}\right.$ for $\left.15 \mathrm{~min}\right)$ denatured catalase were controls. After incubation at $26^{\circ} \mathrm{C}$, daily examination for the microbial growth and colony formation on agar plate was performed, with the day of first observation of colonies recorded as detection time.

\section{Beer-Spoilage Capacity Evaluation}

The "growth in beer test" had been performed to study the beer-spoilage capability of L. brevis BM-LB13908
(Sakamoto and Konings, 2003). Approximately $10^{5}$ cells $/ \mathrm{mL}$ of logarithmic growing, VBNC, and recovered cells were inoculated into finished degassed beer under sterile conditions at $26^{\circ} \mathrm{C}$. Non-inoculated beer was served as control. The inoculated and non-inoculated beers were examined visually every day for turbidity for 30 days. At day 30, lactic acid and acetic acid concentrations were detected by reversed-phase high performance liquid chromatography (HPLC) and quantified by external standard method (Deng et al., 2015). Fifty $\mu \mathrm{L}$ of cell samples collected by centrifugation and filter was injected into the 1100 series HPLC system (Agilent, United States). Compounds were separated on a $250 \times 4.60 \mathrm{~mm}, 4 \mu \mathrm{m}$ Synergi Hydro-RP $80 \AA$ A column (Phenomenex, Lane Cove, Australia) at $30^{\circ} \mathrm{C}$. The mobile phase was $0.43 \%$ orthophosphoric acid with a flow rate of $1.0 \mathrm{~mL} / \mathrm{min}$, and elution was monitored by $210 \mathrm{~nm}$ UV detection.

\section{Statistical Analysis}

All the experiments were conducted in triplicate. Data are presented as mean \pm standard deviation (SD) of three independent biological replicates. Statistical comparisons were made by one-way analysis of variance followed by Tukey's comparison test (XLstat software). The $p$-value $<0.05$ was considered to be significant in this study.

\section{RESULTS AND DISCUSSION}

\section{Formation of VBNC State}

For low-temperature storage, despite a low decrease in viable cells showing a final concentration of $10^{5}$ cells $/ \mathrm{mL}$, whole population of $L$. brevis cells were no longer culturable after $189 \pm 5.7$ days (Figure 1A). According to the continuous

TABLE 1 | Results of beer-spoilage ability test.

\begin{tabular}{llccc}
\hline Strain & State & Turbidity & Lactic acid (mg/L) & Acetic acid (mg/L) \\
\hline Fresh beer & & - & $86.45 \pm 23.61^{\mathrm{a}}$ & $75.77 \pm 25.23^{\mathrm{a}}$ \\
Lactobacillus brevis BM-LB13908 & Normal & + & $191.86 \pm 38.15^{\mathrm{b}}$ & $189.57 \pm 41.75^{\mathrm{b}}$ \\
& VBNC & + & $181.28 \pm 37.87^{\mathrm{b}}$ & $172.39 \pm 35.92^{\mathrm{b}}$ \\
& Recovered & + & $201.45 \pm 32.46^{\mathrm{b}}$ & \\
\hline
\end{tabular}

+, positive; -, negative. The different superscript letters in the same column indicate difference among concentrations at 0.05 level. 
passage in beers, formation of VBNC state of $L$. brevis strain BM-LB13908 was found with $27 \pm 1.2$ subcultures (Figure 1B). The present results had verified the induction on VBNC state of L. brevis by simulating conditions during beer brewing. It was also found that the culturability of L. brevis declined significantly during conditions induced by beer subculture or low temperature, indicating the VBNC L. brevis could be potentially neglected in brewery environments due to incapability of detection by traditional culture methods. As Lactobacillus strains were concerned, up to date, a total of five species have been validated for VBNC state formation, including L. lindneri (Suzuki et al., 2006; Liu et al., 2017a), L. casei (Liu et al., 2017c), L. plantarum (Liu et al., 2017b), L. paracollinocides, (Suzuki et al., 2006) and L. acetotolerans (Deng et al., 2015), which had been induced to enter into VBNC state by either low-temperature storage or beer subculture treatment. Consequently, this is the first the formation and recovery of VBNC state by the species of L. brevis as the most common beer spoilage and hop resistance strain.

\section{VBNC Cells Recovery}

Viable but nonculturable cells of L. brevis strain BM-LB13908 induced by low-temperature storage or beer subculture had been treated by addition of Tween- 20 or-80, vitamin $\mathrm{C}$ or B2, with $<10 \mathrm{CFU} / \mathrm{mL}$ culturable cells acquired. However, 16 colonies (160 CFU/mL cells) appeared on MRS agar supplemented with catalase at day 3. Thus, VBNC L. brevis cells regained culturability on media containing catalase. Importantly, no colony appeared on the MRS agar plates with no supplementation and addition of heat-denatured catalase. Heat denaturation of catalase deferred the recovery process, verifying catalase addition is capable of recovery of VBNC L. brevis cells. Such finding suggested the potential improvement for brewers on the microbiological quality control by culture methodology with catalase supplementation. It has been reported that transfer of cells to nutrient-rich environment initiates a metabolic imbalance, thus leading to a rapid production of superoxide and free radicals (Bloomfield et al., 1998). Furthermore, the antibacterial function of hop compounds has been reported to associate with efficient redox reactivity and cause cellular oxidative damage (Behr and Vogel, 2010). One possible explanation is the VBNC L. brevis cells are under environmental stress and sensitive to detoxify superoxide during active phenotypic adaptation to beer environment with high concentration of hop bitter compounds, and antioxidant capacity of catalase may alleviate these stress conditions, leading to the recovery of $\mathrm{VBNC}$ cells by addition of catalase.

\section{Beer-Spoilage Capacity}

According to the results, the logarithmic, VBNC, and recovered cells of L. brevis strain BM-LB13908 were capable of causing turbidity in beer within a length of approximate 7 days (data not shown), suggesting its maintenance of beer-spoilage capability in both VBNC and recovered state. No turbidity was observed in the non-inoculated beer. In addition, higher level of both lactic acid and acetic acid were found after incubation for 30 days, which may eventually lead to beer acidizing (Table 1). It indicates both VBNC and recovered cells retained as similar level of viability and metabolic activity as logarithmic cells, which was in accordance with previous studies (Rahman et al., 2001; Jolivet-Gougeon et al., 2006; Du et al., 2007; Imazaki and Nakaho, 2009; Ordax et al., 2009; Buck and Oliver, 2010; Patrone et al., 2013). As the most commonly identified spoilage microorganism in beer industry, L. brevis is capable of VBNC formation under common food storage condition (low-temperature), recovery by addition of catalase, as well as maintained production of lactic acid and acetic acid, which may be the leading cause for a wide range of beer spoilage cases. In addition, it indicated that the normal, VBNC, and recovered L. brevis cells are capable of causing spoilage within the storage life of beer.

\section{CONCLUSION}

In conclusion, this is the first report on the VBNC induction and recovery of L. brevis, as well as beer-spoilage ability of both VBNC and recovered cells. For L. brevis strain BMLB13908 in the present study, VBNC formation and recovery, as well as maintenance of beer spoilage capability have been verified, which indicated $L$. brevis strain could cause beer spoilage due to incapability of detection by routine methodologies. The results derived from this study may aid in further study on L. brevis and other hop-resistance bacteria, and guidance on the prevention and control of beer spoilage, such as improvement for brewers on the microbiological quality control by using the improved culture method with catalase supplementation.

\section{AUTHOR CONTRIBUTIONS}

ZX and YD conceived of the study and participated in its design and coordination. JL and YD performed the experimental work. LL, JS, and BL analyzed the data. JL, YL, BP, MS, and ZX prepared and revised this manuscript. All authors reviewed and approved the final manuscript.

\section{FUNDING}

This work was supported by the National Key Research and Development Program of China (2016YFD04012021 and 2016YFD0400203), the National Key Technology R\&D Program (2012BAD37B01), the National 973-Plan of China (2012CB720800), Guangdong Special Support Program (2016TQ03N682), Pearl River S\&T Nova Program of Guangzhou (201710010061), Science and Technology Planning Project of Guangdong Province (2017A050501007), National Outstanding Doctoral Dissertation Funding (201459), the Fundamental Research Funds for the Central Universities (2017ZD092), and the 111 Project (B17018). 


\section{REFERENCES}

Behr, J., and Vogel, R. F. (2010). Mechanisms of hop inhibition include the transmembrane redox reaction. Appl. Environ. Microbiol. 76, 142-149. doi: 10.1128/AEM.01693-09

Berney, M., Hammes, F., Bosshard, F., Weilenmann, H. U., and Egli, T. (2007). Assessment and interpretation of bacterial viability by using the LIVE/DEAD BacLight Kit in combination with flow cytometry. Appl. Environ. Microbiol. 73, 3283-3290. doi: 10.1128/AEM.02750-06

Bloomfield, S. F., Stewart, G. S., Dodd, C. E., Booth, I. R., and Power, E. G. (1998). The viable but nonculturable phenomenon explained? Microbiology 144, 1-3. doi: 10.1099/00221287-144-1-1

Buck, A., and Oliver, J. D. (2010). Survival of spinach-associated Helicobacter pylori in the viable but nonculturable state. Food Control 21, 1150-1154. doi: 10.1016/j.foodcont.2010.01.010

Chattopadhyay, M. K., Raghu, G., Sharma, Y. V., Biju, A. R., Rajasekharan, M. V., and Shivaji, S. (2011). Increase in oxidative stress at low temperature in an Antarctic bacterium. Curr. Microbiol. 62, 544-546. doi: 10.1007/s00284-0109742-y

Deng, Y., Liu, J., Li, L., Fang, H., Tu, J., Li, B., et al. (2015). Reduction and restoration of culturability of beer-stressed and low-temperature-stressed Lactobacillus acetotolerans strain 2011-8. Int. J. Food Microbiol. 206, 96-101. doi: 10.1016/j.ijfoodmicro.2015.04.046

Dinu, L. D., and Bach, S. (2011). Induction of viable but nonculturable Escherichia coli O157:H7 in the phyllosphere of lettuce: a food safety risk factor. Appl. Environ. Microb. 77, 8295-8302. doi: 10.1128/AEM.050 20-11

Du, M., Chen, J., Zhang, X., Li, A., Li, Y., and Wang, Y. (2007). Retention of virulence in a viable but nonculturable Edwardsiella tarda isolate. Appl. Environ. Microbiol. 73, 1349-1354. doi: 10.1128/AEM.02243-06

Garofalo, C., Osimani, A., Milanović, V., Taccari, M., Aquilanti, L., and Clementi, F. (2015). The occurrence of beer spoilage lactic acid bacteria in craft beer production. J. Food Sci. 80, 2845-2852. doi: 10.1111/1750-3841. 13112

Griffitt, K. J., Noriea, N. F., Johnson, C. N., and Grimes, D. J. (2011). Enumeration of Vibrio parahaemolyticus in the viable but nonculturable state using direct plate counts and recognition of individual gene fluorescence in situ hybridization. J. Microbiol. Methods 85, 114-118. doi: 10.1016/j.mimet.2011. 02.006

Gupte, A. R., Rezende, C. L., and Joseph, S. W. (2003). Induction and resuscitation of viable but nonculturable Salmonella enterica Serovar Typhimurium DT104. Appl. Environ. Microbiol. 69, 6669-6675. doi: 10.1128/AEM.69.11.6669-6675. 2003

Hobbie, J. E., Daley, R. J., and Jasper, S. (1977). Use of nucleopore filters for counting bacteria by fluorescence microscopy. Appl. Environ. Microbiol. 33, 1225-1228.

Imazaki, I., and Nakaho, K. (2009). Temperature-upshift-mediated revival from the sodium-pyruvate-recoverable viable but nonculturable state induced by low temperature in Ralstonia solanacearum: linear regression analysis. J. Gen. Plant Pathol. 75, 213-226. doi: 10.1007/s10327-009-0166-0

Jallouli, W., Zouari, N., and Jaoua, S. (2010). Involvement of oxidative stress and growth at high cell density in the viable but nonculturable state of Photorhabdus temperata ssp. temperata strain K122. Process Biochem. 45, 706-713. doi: $10.1016 /$ j.procbio.2010.01.007

Jolivet-Gougeon, A., Sauvager, F., Bonnaure-Mallet, M., Colwell, R. R., and Cormier, M. (2006). Virulence of viable but nonculturable S Typhimurium LT2 after peracetic acid treatment. Int. J. Food. Microbiol. 112, 147-152. doi: 10.1016/j.ijfoodmicro.2006.06.019

Kong, H. G., Bae, J. Y., Lee, H. J., Joo, H. J., Jung, E. J., Chung, E., et al. (2014). Induction of the viable but nonculturable state of Ralstonia solanacearum by low temperature in the soil microcosm and its resuscitation by catalase. PLOS One 9:e109792. doi: 10.1371/journal.pone.0109792

Kong, I. S., Bates, T. C., Hülsmann, A., Hassan, H., Smith, B. E., and Oliver, J. D. (2004). Role of catalase and oxyR in the viable but nonculturable state of Vibrio vulnificus. FEMS Microbial. Ecol. 50, 133-142. doi: 10.1016/j.femsec.2004. 06.004

Lawrence, D. R. (1988). "Spoilage organisms in beer," in Developments in Food Microbiology, ed. R. K. Robinson (London: Elsevier), 1-48.
Lin, J., Chen, X. Y., Chen, C. Y., Hu, J. T., Zhou, C. L., Cai, X. F., et al. (2018). Durably antibacterial and bacterially antiadhesive cotton fabrics coated by cationic fluorinated polymers. ACS Appl. Mater. Inter. 10, 6124-6136. doi: 10.1021/acsami.7b16235

Liu, J., Li, L., Li, B., Peters, B. M., Deng, Y., Xu, Z., et al. (2017a). First study on the formation and resuscitation of viable but nonculturable state and beer spoilage capability of Lactobacillus lindneri. Microb. Pathog. 107, 219-224. doi: 10.1016/j.micpath.2017.03.043

Liu, J., Li, L., Li, B., Peters, B. M., Deng, Y., Xu, Z., et al. (2017b). Study on spoilage capability and VBNC state formation and recovery of Lactobacillus plantarum. Microb. Pathog. 110, 257-261. doi: 10.1016/j.micpath.2017.06.044

Liu, J., Li, L., Peters, B. M., Li, B., Chen, L., Deng, Y., et al. (2017c). The viable but nonculturable state induction and genomic analyses of Lactobacillus casei BMLC14617, a beer-spoilage bacterium. Microbiologyopen 6:e506. doi: 10.1002/ mbo3.506

Liu, J., Zhou, R., Li, L., Peters, B. M., Li, B., Lin, C.-w., et al. (2017d). Viable but nonculturable state and toxin gene expression of enterohemorrhagic Escherichia coli O157 under cryopreservation. Res. Microbiol. 168, 188-193. doi: 10.1016/ j.resmic.2016.11.002

Magajna, B. A., and Schraft, H. (2015). Campylobacter jejuni biofilm cells become viable but non-culturable (VBNC) in low nutrient conditions at $4{ }^{\circ} \mathrm{C}$ more quickly than their planktonic counterparts. Food Control 50, 45-50. doi: 10.1016/j.foodcont.2014.08.022

Marcobal, A., Martín-Alvarez, P. J., Moreno-Arribas, M. V., and Muñoz, R. (2006). A multifactorial design for studying factors influencing growth and tyramine production of the lactic acid bacteria Lactobacillus brevis CECT 4669 and Enterococcus faecium BIFI-58. Res. Microbiol. 157, 417-424. doi: 10.1016/j. resmic.2005.11.006

Mary, P., Chihib, N. E., Charafeddine, O., Defives, C., and Hornez, J. P. (2002). Starvation survival and viable but nonculturable state in Aeromonas hydrophila. Microbial. Ecol. 43, 250-258. doi: 10.1007/s00248-001-0046-4

Miao, J., Liang, Y., Chen, L., Wang, W., Wang, J., Li, B., et al. (2017). Formation and development of Staphylococcus biofilm: With focus on food safety. J. Food Safety 37:e12358. doi: 10.1111/jfs. 12358

Oliver, J. D. (2005). The viable but nonculturable state in bacteria. J. Microbiol. 43, 93-100.

Ordax, M., Biosca, E. G., Wimalajeewa, S. C., López, M. M., and Marco-Noales, E. (2009). Survival of Erwinia amylovorain mature apple fruit calyces through the viable but nonculturable (VBNC) state. J. Appl. Microbiol. 107, 106-116. doi: 10.1111/j.1365-2672.2009.04187.x

Patrone, V., Campana, R., Vallorani, L., Dominici, S., Federici, S., Casadei, L., et al. (2013). CadF expression in Campylobacter jejuni strains incubated under low-temperature water microcosm conditions which induce the viable but nonculturable (VBNC) state. Antonie Van Leeuwenhoek 103, 979-988. doi: 10.1007/ s10482-013-9877-5

Premont, R. T., Gainetdinov, R. R., and Caron, M. G. (2001). Following the trace of elusive amines. Proc. Natl. Acad. Sci. U.S.A. 98, 9474-9475. doi: 10.1073/pnas. 181356198

Rahman, M. H., Suzuki, S., and Kawai, K. (2001). Formation of viable but nonculturable state (VBNC) of Aeromonas hydrophila and its virulence in goldfish, Carassius auratus. Microbiol. Res. 156, 103-106. doi: 10.1078/0944-501300084

Ramaiah, N., Ravel, J., Straube, W. L., Hill, R. T., and Colwell, R. R. (2002). Entry of Vibrio harveyi and Vibrio fischeri into the viable but nonculturable state. J. Appl. Microbiol. 93, 108-116. doi: 10.1046/j.1365-2672.2002.01666.x

Sakamoto, K., and Konings, W. N. (2003). Beer spoilage bacteria and hop resistance. Int. J. Food Microbiol. 89, 105-124. doi: 10.1016/S0168-1605(03) 00153-3

Simpson, W. J. (1993). Ionophoric action of trans-isohumulone on Lactobacillus brevis. J. Gen. Microbiol. 139, 1041-1045. doi: 10.1099/00221287-139-5-1041

Simpson, W. J., and Fernandez, J. L. (1992). Factors affecting antibacterial activity of hop compounds and their derivatives. J. Appl. Bacteriol. 72, 327-334. doi: 10.1111/j.1365-2672.1992.tb01843.x

Simpson, W. J., and Fernandez, J. L. (1994). Mechanism of resistance of lactic acid bacteria to trans-isohumulone. J. Am. Soc. Brew. Chem. 52, 9-11. doi: 10.1094/ASBCJ-52-0009

Sun, F., Chen, J., Zhong, L., Zhang, X. H., Wang, R., Guo, Q., et al. (2008). Characterization and virulence retention of viable but nonculturable Vibrio 
harveyi. FEMS Microbiol. Ecol. 64, 37-44. doi: 10.1111/j.1574-6941.2008.00 442.x

Suzuki, K., Iijima, K., Asano, S., Kuriyama, H., and Kitagawa, Y. (2008). Development of detection medium for hard-to-culture beer-spoilage lactic acid bacteria. J. Appl. Microbiol. 104, 1458-1470. doi: 10.1111/j.1365-2672.2007. 03669.x

Suzuki, K., Iijima, K., Sakamoto, K., Sami, M., and Yamashita, H. (2006). A review of hop resistance in beer spoilage lactic acid bacteria. J. Int. Brew. 112, 173-191. doi: 10.1002/j.2050-0416.2006.tb00247.x

Suzuki, K., Sami, M., Kadokura, H., Nakajima, H., and Kitamoto, K. (2002). Biochemical characterization of horA-independent hop resistance mechanism in Lactobacillus brevis. Int. J. Food Microbiol. 76, 223-230. doi: 10.1016/S01681605(02)00016-8

Xu, Z., Xie, J., Peters, B. M., Li, B., Li, L., Yu, G., et al. (2017). Longitudinal surveillance on antibiogram of important gram-positive pathogens in Southern China, 2001 to 2015. Microb. Pathog. 103, 80-86. doi: 10.1016/j.micpath.2016. 11.013
Zeng, B., Zhao, G., Cao, X., Yang, Z., Wang, C., and Hou, L. (2013). Formation and resuscitation of viable but nonculturable Salmonella typhi. Biomed. Res. Int. 2013:907170. doi: $10.1155 / 2013 / 907170$

Conflict of Interest Statement: The authors declare that the research was conducted in the absence of any commercial or financial relationships that could be construed as a potential conflict of interest.

The reviewer MC and handling Editor declared their shared affiliation.

Copyright (C) 2018 Liu, Deng, Soteyome, Li, Su, Li, Li, Shirtliff, Xu and Peters. This is an open-access article distributed under the terms of the Creative Commons Attribution License (CC BY). The use, distribution or reproduction in other forums is permitted, provided the original author(s) and the copyright owner(s) are credited and that the original publication in this journal is cited, in accordance with accepted academic practice. No use, distribution or reproduction is permitted which does not comply with these terms. 